Phosphorus Research Bulletin Vol. 35 (2019) pp. 038-041

\title{
ELECTRICAL PROPERTIES OF HUMAN BONE AS AN ELECTRET
}

\author{
Soichiro Itoh ${ }^{1 *}$, Kimihiro Yamashita ${ }^{1,2,3}$ \\ (* Corresponding author: itoso.gene@gmail.com)
}

${ }^{1}$ Strategic Innovation Research Hub, Laboratory of Strength of Material and Science, Teikyo University, 2-11-1, Kaga, Itabashi-ku, Tokyo, 173-8605, Japan.

${ }^{2}$ School of Medical and Dental Sciences, Tokyo Medical and Dental University, 1-5-45 Yushima, Bunkyo, Tokyo 113-8510.

${ }^{3}$ Department of Applied Chemistry, School of Advanced Engineering, Kogakuin University, 2665-1, Nakano, Hachioji, Tokyo 192-0015, Japan.

Keywords: Human bone, Electrical property, Bone piezoelectricity, Electrical polarization

\begin{abstract}
We analyzed the electrical properties of human bone in comparison with the electrically polarized and nonpolarized bone specimens and discussed the role of an organic and inorganic matrix of bone in bone piezoelectricity. Femoral neck bone was scanned to evaluate the cancellous bone structures using micro-computed tomography, and we quantified the carbonic acid by attenuated total reflection spectra to estimate carbonate apatite. The stored electrical charge in the electrically polarized and nonpolarized bone specimens were calculated using thermally stimulated depolarized current (TSDC) measurements. Each TSDC curve had 3 peaks at $100^{\circ} \mathrm{C}, 300^{\circ} \mathrm{C}$ and $500^{\circ} \mathrm{C}$, which may be attributed to collagen, carbonate apatite and hydroxyapatite, respectively. It is suggested that organic substances are more effectively electrically polarized than apatite minerals and that the stored charge in bone may be affected by total bone mass and bone quality, including 3-dimensional structure and structural composition.
\end{abstract}

(Received Jun 30, 2019; Accepted Jul 25,2019)

\section{INTRODUCTION}

When the mechanical stress is impressed upon bone, the internal architecture of the trabeculae undergoes adaptive changes and secondary change of the external cortical portion of the bone occurs. As a result, an electrical potential is induced in the bone. This phenomenon was propounded first by Wolf and is well known as bone piezoelectricity ${ }^{1}$. The areas of bone under tension develop positive potentials, whereas those under compression develop negative potentials. Furthermore, it is reported that living bone becomes thicker on its compressed concave side and thinner on its tensed convex $\operatorname{side}^{2}$. This fact suggests that a polarized region may exist in living bone, which means bone is an electret, and that the negative and positive potentials may affect bone remodeling cooperatively. In this case, it is assumable that mineral crystals and collagen play a cooperative role in bone piezoelectricity. To clarify this mechanism, we characterized the electrical properties of human bone specimens and examined their relationship with the cancellous bone structures and the mineral crystals including carbonate apatite. Furthermore, we attempted electrical polarization of living bone to progress its ability as an electret. ${ }^{3-5}$

\section{MATERIALS AND METHODS}

The research protocol was approved by the ethics committees of the institutions that the authors are affiliated with and was conducted according to the Declaration of Helsinki. Informed consent was obtained from each candidate. Femoral neck bone was harvested during hemiarthroplasty surgeries of femoral neck fracture. After temporary storage at 
$-20^{\circ} \mathrm{C}$, the specimens were sliced into $1 \mathrm{~mm}$ thick pieces using a diamond saw (IsoMet $^{\circledR}$ Low Speed Saw, Buehler, Illinois, USA), washed with distilled water, dried at $40^{\circ} \mathrm{C}$ and used for the experiment.

\section{Measurement of thermally stimulated depolarization current}

The bone specimens were clamped with a pair of platinum electrodes and were covered with alumina plates to form a bilayer. The thermally stimulated depolarized current (TSDC) measurements were performed using an electric current measuring unit (6514 system electrometer, Keithley, Ohio, USA). The sample temperature was increased at a heating rate of $5.0^{\circ} \mathrm{C} / \mathrm{min}$ from $25^{\circ} \mathrm{C}$ to $650^{\circ} \mathrm{C}$, and the depolarization current was measured. The total stored charges in the bone samples were calculated using the following formula:

$$
Q=1 / \beta \int J(t) d t
$$

where $\mathrm{Q}$ is the total stored charge $\left(\mathrm{nC} \cdot \mathrm{cm}^{-2}\right), \beta$ is the temperature ramp rate $\left(\mathrm{K} \cdot \mathrm{s}^{-2}\right)$, and $\mathrm{J}(\mathrm{t})$ is the electric current density $\left(\mathrm{nA} \cdot \mathrm{cm}^{-2}\right),{ }^{6,7}$

\section{Micro computed tomography scanning}

The specimens, which bordered the sliced bones that were used for the TSDC measurements, were scanned to evaluate the cancellous bone structures using micro computed tomography (CT) (smx100, Shimazu, Tokyo, Japan), which was analyzed using computer analysis software (3D-BON, LATOC, Tokyo, Japan). The primary parameters including the bone mineral content (BMC), the bone volume (BV), the tissue volume (TV), trabecular thickness (Tb. Th), trabecular number $(\mathrm{Tb} . \mathrm{N})$, trabecular separation $(\mathrm{Tb}$. $\mathrm{Sp})$ and trabecular spacing (Tb. Spac) were evaluated. The secondary parameters including the $\mathrm{BV} /$ trabecular bone, the bone mineral density (BMD) and the $\mathrm{BMC} / \mathrm{TV}$ were calculated.

Quantification of the carbonic acid to estimate carbonate apatite in bone specimens

Because carbonate apatite was expected to be characteristic of human bone, the carbonic acid was quantified by attenuated total reflection (ATR) spectra. ATR spectra of the bone specimens were recorded in the range of $400 / \mathrm{cm}$ to $4000 / \mathrm{cm}$ using an ATR spectrophotometer (Thermo Scientific, Nicolet is50, MA, USA).

The peak intensity of the carbonate, which is characteristic of type B carbonate apatite ${ }^{8}$, and of the phosphate ion, which correlates with the amount of phosphate $^{9}$, were recorded at $871 / \mathrm{cm}$ and $559 / \mathrm{cm}$, respectively (Fig. 1). The peak intensities of the carbonate and phosphate ions were analyzed using the instrument software (Thermo Scientific, OMNIC, MA, USA). The ratio of the two peak intensities was calculated to estimate the ratio of carbonate ions to phosphate ions $\left(\mathrm{CO}_{3} / \mathrm{PO}_{4}\right.$ ratio $)$ in the bone specimens.

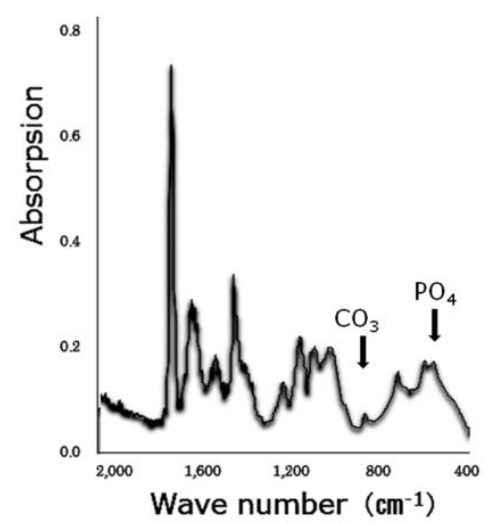

Fig. 1. The peak intensity of $\mathrm{CO}_{3}$ and $\mathrm{PO}_{4}$

\section{Polarization treatment of bone}

The bone specimens were clamped with a pair of platinum electrodes and electrically polarized in direct current electric fields of $1.5 \mathrm{kV} / \mathrm{cm}$ in air at $25^{\circ} \mathrm{C}$. Their total stored charges were similarly measured by integrating the TSDC curve and correlation between the BMD was evaluated. The group of polarized bone specimens taken from the same cases were assumed at present to have the same BMD.

\section{Statistical analysis}

The stored charge before and after electrical polarization were compared using a Mann-Whitney test. Correlative analyses of the secondary parameters calculated using the trabecular bone analysis, $\mathrm{CO}_{3} / \mathrm{PO}_{4}$ ratio and the stored charge before and after electrical polarization for the bone specimens were performed using Spearman's rank correlation coefficient test. Furthermore, the best-fit model was computed using a simple regression analysis, which compared the parameters with a significant difference. A p value of $<0.05$ was considered to be statistically significant.

\section{RESULTS}

Baseline characteristics of patients including gender, average age and calculated parameters of bone structure of specimens are summarized in Table 1 .

Each TSDC curve of bone specimens had peaks at $100^{\circ} \mathrm{C}, 300^{\circ} \mathrm{C}$ and $500^{\circ} \mathrm{C}$ before and after electrical polarization (Fig. 2A, 2B). 


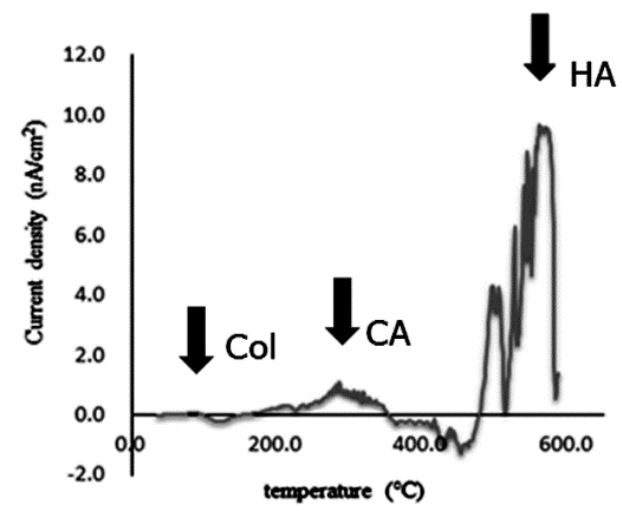

Fig. 2A. TSDC curve of bone specimens before polarization

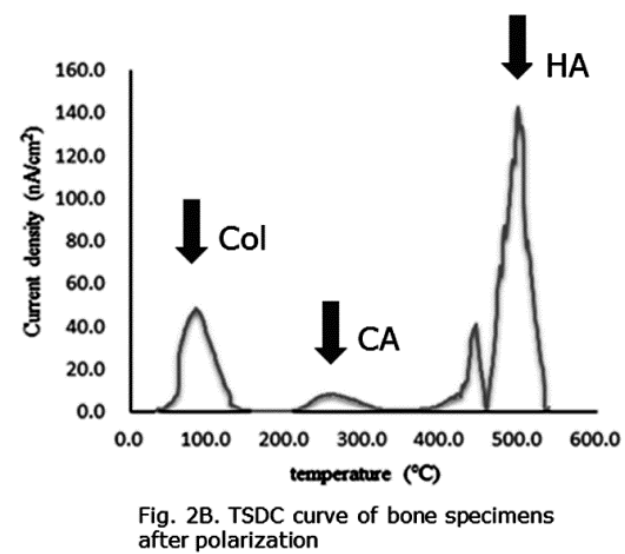

The $\mathrm{CO}_{3} / \mathrm{PO}_{4}$ ratios and the stored charge in the bone specimens before and after polarization are summarized in Table 2. After polarization, the stored charge around each peak and the total stored charge were significantly larger than those before polarization (each $\mathrm{p}<0.01$ ).

There was a significant positive correlation between BMD and the stored charge around the $500^{\circ} \mathrm{C}$ peak and BMD and the total stored charge in the nonpolarized bone specimens (each p<0.05) (Fig. 3A, 3B).

Meanwhile, there was a significant negative correlation between $\mathrm{BMD}$ and the $\mathrm{CO}_{3} / \mathrm{PO}_{4}$ ratio $(\mathrm{p}<0.05)$ (Fig. 3C).

The equations for these parameters are shown, respectively, as below:

$\mathrm{Y}=0.0242 \mathrm{X}+0.0282\left(\mathrm{R}^{2}=0.1425\right)$

where $\mathrm{Y}$ is the stored bone charge around the $500^{\circ} \mathrm{C}$ peak $\left(\mu \mathrm{C} / \mathrm{cm}^{2}\right)$ and $\mathrm{X}$ is BMD $\left(\mathrm{mg} / \mathrm{cm}^{3}\right)$. $\mathrm{Y}=0.0287 \mathrm{X}+2.3555\left(\mathrm{R}^{2}=0.1383\right)$

where $\mathrm{Y}$ is the total stored bone charge $\left(\mu \mathrm{C} / \mathrm{cm}^{2}\right)$

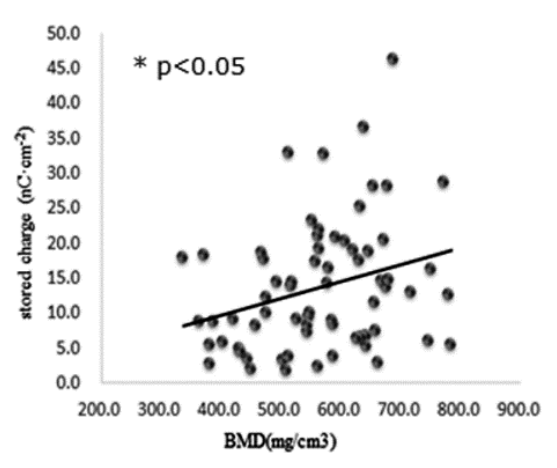

Fig. 3A. BMD and the stored charge around the $500^{\circ} \mathrm{C}$ peak

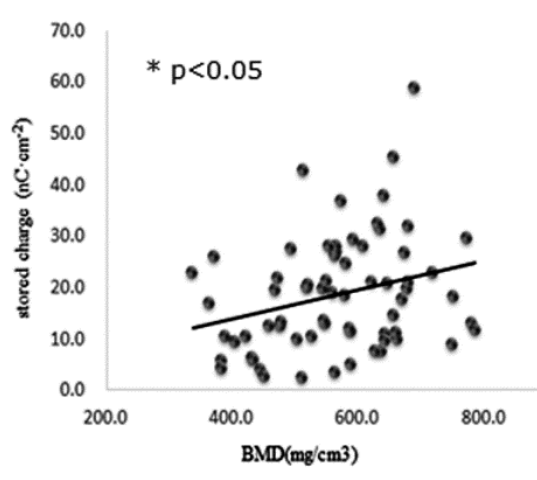

Fig. 3B. BMD and the total stored charge

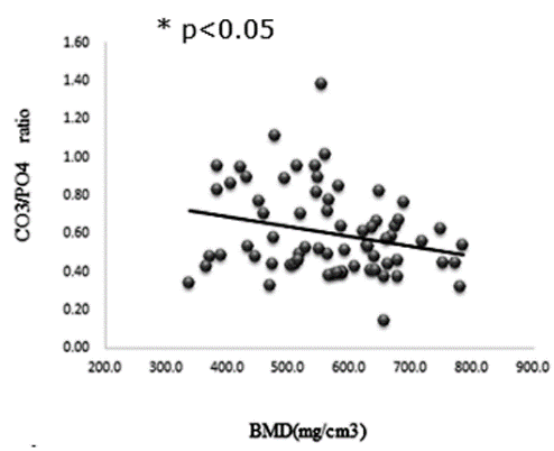

Fig. 3C. BMD and $\mathrm{CO}_{3} / \mathrm{PO}_{4}$

and $\mathrm{X}$ is $\mathrm{BMD}\left(\mathrm{mg} / \mathrm{cm}^{3}\right)$.

$\mathrm{Y}=-0.0005 \mathrm{X}+0.8930\left(\mathrm{R}^{2}=0.1101\right)$

where $\mathrm{Y}$ is the $\mathrm{CO}_{3} / \mathrm{PO}_{4}$ ratio and $\mathrm{X}$ is $\mathrm{BMD}$ $\left(\mathrm{mg} / \mathrm{cm}^{3}\right)$.

However, there was no correlation between the examined parameters in the bone specimens after electrical polarization.

Table 1. Gender, average age and calculated parameters of bone structure of specimens. Average \pm SD

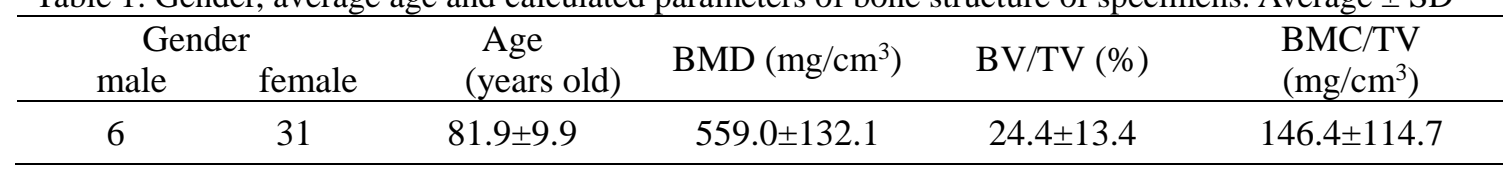


Table 2. The $\mathrm{CO}_{3} / \mathrm{PO}_{4}$ ratio and the stored charge in the bone specimens before and after polarization. Average \pm SD. After polarization, the stored charge around each peak and the total stored charge have increased significantly.

\begin{tabular}{cccccc}
\hline & $\mathrm{CO}_{3} / \mathrm{PO}_{4}$ & $\begin{array}{c}\mathrm{Q}\left(100^{\circ} \mathrm{C}\right) \\
\left(\mathrm{uC} / \mathrm{cm}^{2}\right)\end{array}$ & $\begin{array}{c}\mathrm{Q}\left(300^{\circ} \mathrm{C}\right) \\
\left(\mathrm{uC} / \mathrm{cm}^{2}\right)\end{array}$ & $\begin{array}{c}\mathrm{Q}\left(500^{\circ} \mathrm{C}\right) \\
\left(\mathrm{uC} / \mathrm{cm}^{2}\right)\end{array}$ & $\begin{array}{c}\text { Total Q } \\
\left(\mathrm{uC} / \mathrm{cm}^{2}\right)\end{array}$ \\
\hline before polarization & $0.62 \pm 0.26$ & $0.9 \pm 1.7$ & $2.6 \pm 3.4$ & $11.3 \pm 8.4$ & $16.2 \pm 10.6$ \\
after polarization & - & $23.8 \pm 28.6$ & $9.5 \pm 11.8$ & $27.6 \pm 30.6$ & $60.9 \pm 53.8$ \\
\hline
\end{tabular}

\section{DISCUSSION}

The theory of bone piezoelectricity propounds that the mechanical stress-induced electric charges in bone may influence bone remodeling through Wolff's law $^{10}$. We have reported previously that TSDC curves of rabbit and bovine bones have two significant peaks at $100^{\circ} \mathrm{C}$ and $500^{\circ} \mathrm{C}^{11}$. The result demonstrates successfully that bone is electrically charged, that is bone is an electret. We considered that the peak at $100^{\circ} \mathrm{C}$ may be attributed to organic substances, collagen fibrils, and the peak at $500^{\circ} \mathrm{C}$ to apatite minerals. In this study, we have found that the TSDC curve of human bone has 3 peaks at $100^{\circ} \mathrm{C}, 300^{\circ} \mathrm{C}$ and $500^{\circ} \mathrm{C}$. Considering that human bone consists of an organic matrix including collagen, and mineral substances including apatite minerals, the peaks at $300^{\circ} \mathrm{C}$ and $500^{\circ} \mathrm{C}$ are expected to be attributed to 2 different types of apatite minerals. Because the minerals in calcined bone specimens are converted to hydroxyapatite with a loss of organic content and carbonate ions during the calcification ${ }^{11}$, the peak at $500^{\circ} \mathrm{C}$ is expected to be attributed to hydroxyapatite. Meanwhile, considering that calcium phosphate and calcium carbonate are the primary mineral components of human bone, the peak at $300^{\circ} \mathrm{C}$ is predicted to be derived from carbonate apatite. Furthermore, there is a possibility that carbonate apatite is involved in forming the peaks at both $300^{\circ} \mathrm{C}$ and $500^{\circ} \mathrm{C}$. More than one peak or a broad peak was found at $300^{\circ} \mathrm{C}$ in both polarized and nonpolarized bone specimens. Moreover, there was a negative correlation between the $\mathrm{CO}_{3} / \mathrm{PO}_{4}$ ratio and $\mathrm{BMD}$, however, there was no correlation between the $\mathrm{CO}_{3} / \mathrm{PO}_{4}$ peak ratio and the stored charges at approximately $300^{\circ} \mathrm{C}$. These phenomena may result from an inhomogeneous distribution of carbonate ions in human bone.

Very small peak was observed at $100^{\circ} \mathrm{C}$ in the nonpolarized bone specimens. This phenomenon may derive from the fact that the peak of organic substances including collagen, which is recorded under $100^{\circ} \mathrm{C}$, is very small compared with the large peak of inorganic substances including hydroxyapatite at $500^{\circ} \mathrm{C}$. In contrast to this, the peaks at $100^{\circ} \mathrm{C}$ increased largely after polarization, however, the peaks at $300^{\circ} \mathrm{C}$ and $500^{\circ} \mathrm{C}$ increased slightly after polarization. Furthermore, there was a positive correlation between the stored bone charge and the BMD before polarization, however, no significant correlation was found between these parameters after polarization. These results may indicate that organic substances are more effectively electrically polarized than apatite minerals.

Resolution of carriers for electrical polarization of human bone and the roles they play in each substance, especially in carbonated apatite, in the polarization process is an issue that we should address in the future.

\section{REFERENCES}

1. H.M. Frost, Anat. Rec., 226, 403 (1990).

2. H.M. Frost, Anat. Rec., 226, 414 (1990).

3. K. Yamashita, N. Oikawa, T. Umegaki, Chem. Mater., 8, 2697 (1996).

4. M. Ueshima, S. Nakamura, K. Yamashita, $A d v$. Mater., 14, 591 (2002).

5. N. Wada, K. Yamashita et. al., Mater. Res. Bull., 74, 50 (2016).

6. S. Nakamura, H. Takeda, K. Yamashita, J. Appl. Phys., 89, 5386 (2001).

7. S. Itoh, S. Nakamura, M. Nakamura, K. Shinomiya, K. Yamashita, Biomaterials, 27, 5572 (2006).

8. C. Rey, V. Renugopalakrishnan, B. Collins, M.J. Glimcher, Calcified Tissue Int., 49, 251 (1991).

9. R.Z. LeGeros, O.R. Trautz, E. Klein, J.P. LeGeros, Experimentia, 25, 5 (1969).

10. E. Fukada, I. Yasuda, J. Phys. Soc. Jpn., 12, 1158 (1957).

11. M. Nakamura, R. Hiratai, K. Yamashita, J. Biomed. Mater. Res., 100A, 1368 (2012). 